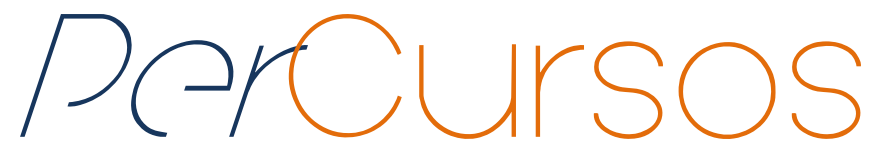

\title{
A mudança linguística, a gramática e a escola
}

\begin{abstract}
Resumo
Tendo a escola como eixo norteador de uma discussão que interessa a pesquisadores-linguistas e professores de língua portuguesa, este artigo se estrutura em torno de duas perguntas: qual é o papel da escola na mudança linguística? E qual é o papel da gramática na escola? São evocados os princípios da sociolinguística variacionista, considerando a abordagem dada ao fator escolarização e os resultados que são depreendidos a partir de sua análise, em duas perspectivas, a da produção e a da percepção, evidenciando a tensão entre frequência de uso e a avaliação social.
\end{abstract}

Palavras-chave: Sociolinguística. Gramática. Frequência de Uso. Avaliação Social.

\section{Raquel Meister Ko. Freitag} Doutora em Linguística pela Universidade Federal de Santa Catarina - UFSC. Professora da Univ. Federal de Sergipe - UFS. Brasil rkofreitag@uol.com.br

\section{Para citar este artigo:}

FREITAG, Raquel Meister Ko.. A mudança linguística, a gramática e a escola. Revista PerCursos,

Florianópolis, v. 18, n.37, p. 63 - 91, maio/ago. 2017.

\section{DOI: $\mathbf{1 0 . 5 9 6 5 / 1 9 8 4 7 2 4 6 1 8 3 7 2 0 1 7 0 6 3}$}

http://dx.doi.org/10.5965/1984724618372017063 


\title{
The linguistic change, the grammar and the school
}

\begin{abstract}
Based on the school as the guiding principle of a discussion that interests to Portuguese-language teachers and linguist researchers, this article is structured around two questions: what is the role of the school in linguistic change? What is the role of grammar in school? The principles of variationist sociolinguistics are evoked, considering the approach given to the schooling factor and. the results are analyzed by two perspectives, the sociolinguistic of production and the sociolinguistic of perception, and these reinforce the tension between frequency of use and social evaluation.
\end{abstract}

Keywords: Sociolinguistics. Grammar. Frequency of Usage. Social Evaluation. 


\section{Introdução}

A heterogeneidade como princípio constitutivo da língua é um pilar da Sociolinguística; este princípio reverbera nos documentos orientadores das práticas pedagógicas do ensino de língua portuguesa no Brasil, como os Parâmetros Nacionais de Língua Portuguesa e, mais recentemente, na Base Nacional Comum Curricular.

A língua é um fenômeno que permite pensar relações com a escola em uma dupla direção: em sendo a língua constitutivamente heterogênea, lidar com a dimensão variável é um desafio da escola. E, tendo a escola como eixo norteador de uma discussão que interessa a pesquisadores-linguistas e professores de língua portuguesa, este artigo se estrutura em torno de duas perguntas: qual é o papel da escola na mudança linguística? E qual é o papel da gramática na escola?

Para a primeira pergunta, são evocados os princípios da sociolinguística variacionista, considerando a abordagem dada ao fator escolarização e os resultados que são depreendidos a partir de sua análise, em duas perspectivas, a da produção e a da percepção.

A segunda pergunta, aparentemente, parece ser desnecessária, haja vista que a discussão sobre a relação entre gramática e escola, no Brasil, vem sendo travada com maior fôlego desde a década de 1980, especialmente a partir dos trabalhos de Carlos Franchi.

Se na década de 1990, especialmente com a publicação dos Parâmetros Nacionais de Língua Portuguesa, a nossa discussão na academia era se deveríamos ensinar gramática, hoje, após uma grande expansão de gramática e gramáticos (MOURA NEVES; CASSEB-GALVÃO, 2014), discutimos como e o que ensinar de gramática na escola.

Quanto ao que ensinar, considerando especialmente as diretrizes preconizadas pelos Parâmetros Curriculares Nacionais de Língua Portuguesa, as pesquisas de 
sociolinguística da produção ${ }^{1}$ têm trazido resultados de fenômenos variáveis, que suscitam discussões em relação ao ensino. A partir de resultados de estudos sociolinguísticos de produção, são levantadas questões relacionadas ao contexto de formalidade da situação ou de condicionamentos do sistema da língua que explicam os direcionais de variação, e estas questões podem levar a sugestões de ensino, como as que são compiladas em Duarte e Ramos (2003), Callou e Lopes (2004), Guy e Zilles (2006), Görski e Coelho (2006, 2009), Coan e Freitag (2010), Brandão e Vieira (2011), Görski \& Freitag (2007, 2013), Martins, Vieira e Tavares (2014), Zilles e Faraco (2015), dentre outros. E, respondendo ao questionamento de Martins, Vieira e Tavares (2014, p. 34), este é o limite das contribuições que os estudos sociolinguísticos de produção podem dar ao ensino: prover resultados de fenômenos variáveis quanto ao encaixamento linguístico e social, que podem ser transformados em sugestões de atividades ou de práticas pedagógicas. Tais sugestões figuram ainda no plano da idealização: não são implementadas nos livros didáticos, por exemplo. O distanciamento entre o plano da idealização e o chão da sala de aula pode ser explicado pelo fato de que não há, ainda, uma área de estudos de interface sociolinguística que vise à testagem da efetividade destas sugestões de atividades e práticas pedagógicas. ${ }^{2}$

Um espaço acadêmico que pode fazer a ponte entre os resultados de estudos de produção sociolinguística e a sua aplicação na sala de aula é, como também preconizam Martins, Vieira e Tavares (2014, p. 35), o Profletras, programa de mestrado profissional em rede na área de ensino de língua portuguesa dirigido a professores do ensino fundamental da rede pública. É neste espaço que encontraremos a receita do como

\footnotetext{
1 "A sociolinguística da produção tem contribuído para a caracterização daquilo que chamamos de 'Português Brasileiro', com descrições de fenômenos variáveis em diferentes níveis linguísticos e em diferentes regiões e estratos sociais. Estudos feitos nessa perspectiva permitem identificar em que contextos surgem novas formas na língua, quais são os fatores estruturais que condicionam a variação, e sugerir direcionais da consciência social do fenômeno com base na distribuição das variantes em função dos fatores sociais controlados na amostra. No entanto, não basta saber como o brasileiro fala; é preciso também conhecer 'como o brasileiro acha que fala', seguindo pela perspectiva da sociolinguística da percepção. [...] A percepção de um fenômeno depende do julgamento do ouvinte, que correlaciona fatores sociais a traços sociolinguísticos, constituindo um padrão de consciência social na comunidade." (FREITAG, SEVERO, ROST-SNICHELOTTO, TAVARES, 2016, p. 65)

${ }^{2}$ Embora existam muitas pesquisas e publicações que se intitulam voltadas para o ensino, de fato o que encontramos são pesquisas sociolinguísticas desenvolvidas no espaço escolar (coleta de dados com alunos da educação básica, por exemplo), o que não é a mesma coisa do que pesquisar estratégias de ensino. Este nicho pode vir a ser ocupado pelas pesquisas de desenvolvimento de produto do Profletras.
} 
ensinar, na medida em que o programa, ao ser voltado para o desenvolvimento de um produto pedagógico, propicia a integração entre resultados descritos e práticas pedagógicas, com a possibilidade de testagem de sua efetividade. Como um dos primeiros resultados deste tipo de abordagem, por exemplo, Martins (2017) apresenta uma proposta que: a) assume uma posição de ensino de língua e gramática; b) sumariza resultados de uma testagem empírica em situação de sala de aula; e c) tece considerações acerca da forma como o conteúdo de gramática está presente nas avaliações parametrizadoras dos sistemas de ensino. Ao testar a aplicação de uma proposta de ensino desenvolvida a partir de resultados de estudos sociolinguísticos em situação real de sala de aula, é possível aferir o que funciona e o que não funciona, o que é utópico e o que é real, dentro de uma agenda para o ensino de gramática, como propõe Vieira (2017). Na construção das linhas mestras desta agenda para o ensino de gramática, considerando as contribuições dos estudos de sociolinguística da produção, o acesso à pluralidade de normas é um dos conceitos centrais. No entanto, é preciso considerar a tensão entre frequência de uso e a avaliação social, para não cairmos no anacronismo que tanto tentamos evitar.

Explicitados os princípios norteadores da resposta à segunda pergunta, passamos para a primeira pergunta, para depois novamente retornar à segunda.

\section{A escola e a mudança linguística}

No Brasil, o nível de escolarização dos informantes é uma variável sociodemográfica padrão para a estratificação das amostras de dados linguísticos, do mesmo modo como é feito com a faixa etária, por exemplo. Esta é uma peculiaridade que só é encontrada na Sociolinguística do Brasil (FREITAG, 2016b): enquanto estudos desenvolvidos nos Estados Unidos consideram grupos dentro de um certo nível de escolarização, como é o caso do estudo de Eckert (1989) sobre os Jokers e Burnouts nas high schools de Detroit, por exemplo, a fim de aferir os efeitos dos pares ou da família no comportamento linguístico dos adolescentes, no Brasil, a escolarização é tomada como variável genérica, controlada com a premissa de que a exposição à cultura letrada e o 
papel normativo da escola levariam o falante ao contato com as variantes canônicas ou de prestígio em uma razão proporcional: quanto maior o nível de escolarização, maior a aderência a estas variantes. Na prática, o que ocorre é que a distribuição de um dado fenômeno variável é correlacionada aos níveis de escolarização e a avaliação social é inferida a partir do resultado.

$\mathrm{Na}$ falta de um controle mais preciso para a classe social - variável presente nos estudos sociolinguísticos realizados fora do Brasil, mas ainda tabu no cenário nacional (cf. FREITAG, 2016b) -, a escolarização assume seu papel, a partir da premissa de que a escola leva à ascensão social. Oficialmente, não existem classes sociais no Brasil, assim como existem níveis de escolarização. Diferentes critérios são utilizados para classificar os brasileiros, a depender dos interesses (classes de consumo, classes de risco de financiamento etc.). Talvez a ausência de uma padronização explique por que tão poucos trabalhos consideram esta variável (ver, por exemplo, Amaral (2003)).

A escolarização, assim como sexo/gênero e faixa etária, é uma variável complexa, que encapsula outros valores. Além disso, não é uma variável estável na história recente do Brasil, com diferentes nomenclaturas e com diferentes arranjos de faixa etária. $O$ controle do nível de escolarização, em longo termo, envolve mudanças no sistema de ensino: primário, ginásio e colegial, primeiro grau e segundo grau, ensino fundamental e ensino médio são nomenclaturas que já foram adotadas para se referir a diferentes níveis de escolarização no Brasil nos últimos 50 anos, o que corresponde ao período de estudos sociolinguísticos e às amostragens de bancos de dados. A diferença de nomenclaturas, exigências e currículos (por exemplo, a passagem do primário ao ginásio se dava mediante exames admissionais, o que não acontece mais com a mudança para primeiro grau e segundo grau) pode levar a assimetrias nas constituições de amostras (FREITAG, 2005, 2011). Estes aspectos precisam ser considerados no momento da comparação de resultados.

A disseminação do controle da escolarização como variável nas amostras sociolinguísticas pode estar relacionada ao fato de que o corpus do projeto NURC Norma Urbana Culta - tenha se detido em documentar a fala de universitários representativos do que seria considerado norma culta, na década de 1960. O projeto 
Competências Básicas do Português (LEMLE; NARO, 1977), por sua vez, teve como amostra falantes oriundos do Mobral, um programa de alfabetização de adultos implantado no Brasil na década de 1970. O contraste entre duas realidades linguísticas tão distintas, marcadas pela acentuada diferença de escolarização, pode sugerir que, entre uma e outra extremidade, haja um contínuo.

Vejamos um contexto variável em que a escolarização tem se mostrado sistematicamente significativa como fator explanatório no português brasileiro: a presença vs. ausência de marcas de concordância.

Ao contrastarem três amostras linguísticas estratificadas quanto ao nível de escolarização, em tempo real, os resultados de Scherre e Naro (2006) mostram um aumento na frequência global da concordância (figura 1), o que, na visão dos autores,

do ponto de vista da apropriação dos bens de prestígio, pode ser visto como um ganho para a comunidade e, do ponto de vista da maior exposição da comunidade ao ambiente escolar, deve ser visto como um fenômeno natural: afinal, os grupos tendem a assimilar, consciente ou inconscientemente, o comportamento linguístico do meio, especialmente quando este comportamento envolve fenômenos sujeitos a estigma e preconceito explícito, como é o caso da concordância de número em português, em particular, no português brasileiro. (SCHERRE; NARO, 2006, p. 109, grifos acrescidos)

Figura 1 - Efeitos dos anos de escolarização no uso da concordância verbal e nominal em duas amostras aleatórias da comunidade do Rio de Janeiro em épocas diferentes

\begin{tabular}{|c|c|c|c|c|}
\hline $\begin{array}{c}\text { Anos de } \\
\text { escolarização }\end{array}$ & Freqüência & $\begin{array}{l}\text { Peso } \\
\text { relativo }\end{array}$ & Freqüência & $\begin{array}{l}\text { Peso } \\
\text { relativo }\end{array}$ \\
\hline \multicolumn{5}{|c|}{ Concordância verbal com todos os dados } \\
\hline & CV-1980-C & & CV-2000-C & \\
\hline $1-4$ & $1.127 / 1.786=63 \%$ & 0.41 & $486 / 650=75 \%$ & 0.32 \\
\hline $5-8$ & $1.370 / 1.760=78 \%$ & 0.53 & $732 / 857=85 \%$ & 0.57 \\
\hline $9-11$ & $889 / 1.089=82 \%$ & 0.53 & $413 / 443=93 \%$ & 0,78 \\
\hline \multicolumn{5}{|c|}{ Concordância nominal com todos os dados } \\
\hline & CN-1980-C & & CN-2000-C & \\
\hline $1-4$ & $2.965 / 4.800=62 \%$ & 0.37 & $1.976 / 2.524=78 \%$ & 0,25 \\
\hline $5-8$ & $3.45 \mathrm{I} / 4.847=71 \%$ & 0.46 & $2.728 / 2.921=93 \%$ & 0.67 \\
\hline $9-11$ & $2.840 / 3.452=82 \%$ & 0.56 & $1.597 / 1.634=98 \%$ & 0.88 \\
\hline \multicolumn{5}{|c|}{ Concordância nominal sem os determinantes da primeira posição } \\
\hline & $\mathrm{CN}-1980-\mathrm{C}$ & & $\mathrm{CN}-2000-\mathrm{C}$ & \\
\hline $1-4$ & $1.144 / 2.930=39 \%$ & 0.37 & $843 / 1.384=61 \%$ & 0,24 \\
\hline $5-8$ & $1.675 / 3.028=55 \%$ & 0,46 & $1.469 / 1.652=89 \%$ & 0.68 \\
\hline $9-11$ & $1.556 / 2.141=73 \%$ & 0.56 & $905 / 941=96 \%$ & 0,88 \\
\hline
\end{tabular}

Fonte: SCHERRE; NARO, 2006, p. 110 
A leitura dos resultados em função da escolarização pressupõe que a exposição ao ambiente escolar leva à conservação das marcas de concordância (com a assimilação, consciente ou inconsciente, da regra e seu valor social). Há que se considerar, no entanto, que: a) o Brasil quase atingiu a universalização da educação básica, com cerca de 94\% da população entre 4 a 17 anos matriculada na escola; ${ }^{3}$ b) a universalização do acesso não tem relação direta com sucesso, o que pode ser mensurado em resultados de avaliações oficiais, como Prova Brasil ou Pisa.

Os resultados das avaliações oficiais sugerem que a universalização do acesso à educação básica não corresponde à universalização do acesso à educação de qualidade. No entanto, os resultados não podem ser vistos de forma descontextualizada. No final de 2016, a mídia deu ampla ênfase aos resultados do Pisa da rede federal, que, destacados do conjunto dos dados nacionais, teria desempenho equivalente ao da Coreia do Sul, país na $11^{\text {a }}$ colocação. Além da carreira, que prevê o estímulo à formação continuada de seus docentes, com incentivos financeiros à titulação (o que eleva qualitativamente o quadro docente), os institutos federais e colégios de aplicação vinculados às universidades federais têm em comum o fato de não terem acesso universalizado como as demais redes: a forma de ingresso se dá por meio de processo seletivo, fazendo com que os alunos que ingressam nestas instituições tenham certo grau de nivelamento de conteúdo, verificado por meio de exame prévio. Do ponto de vista qualitativo, este fato explica, em parte, porque os institutos federais e colégios de aplicação vêm apresentando melhores resultados do que as redes estaduais e municipais nas avaliações oficiais. Estas não são as melhores instituições porque propiciam a melhor formação aos seus alunos; são as melhores instituições porque tem a possibilidade de selecionar os melhores alunos.

Do ponto de vista sociolinguístico, este comportamento sinaliza que a variável escolarização não pode ser considerada apenas e naturalmente como um efeito da

\footnotetext{
${ }^{3}$ Até 2009, a obrigatoriedade de escolarização era da faixa etária dos 7 aos 14 anos. A emenda 59 deu nova redação ao inciso I do artigo 208 da Constituição Federal: "educação básica obrigatória e gratuita dos 4 (quatro) aos 17 (dezessete) anos de idade, assegurada inclusive sua oferta gratuita para todos os que a ela não tiveram acesso na idade própria”. O Censo da Educação Básica de 2016 aponta que, na faixa etária entre 6 e 14 anos, a taxa de matrículas é de 98,6\% da população. Ainda assim, são 2,8 milhões de brasileiros entre 4 e 17 anos que estão fora da escola.
} 
exposição do falante à cultura letrada e a assimilação de suas regras. A escola reflete e reforça as estruturas da sociedade; os resultados de distribuição das variantes, nas análises sociolinguísticas, não podem ser atribuídos exclusivamente à capacidade da escola de influenciar e modelar o padrão linguístico. Estes resultados são também reflexo de práticas sociais extraescolares que são apenas repetidas e reforçadas no espaço da escola. Ao controlar a escolarização do falante com o pressuposto de acesso a bens de cultura letrada, a abordagem sociolinguística assume uma idealização de escola homogênea, neutralizando as diferenças sociais das diferentes escolas, nos diferentes tempos e lugares.

Os resultados do estudo da variação na concordância de número sistematicamente apontam para a relação diretamente proporcional entre o aumento do nível de escolarização e a conservação das marcas. Estes resultados têm sido interpretados como sinalizadores do papel normatizador da escola, refreando uma mudança linguística:

Podemos inferir, então, que a passagem pela escola, no tocante à concordância nominal, surte algum efeito. Não que acreditemos que a escola seja altamente competente: trata-se da ação, mais intensificada pela escola, sobre o efeito social de que se reveste o uso da nãoconcordância. De fato, diferentemente de outros fenômenos de variação do PB (como o de nós/a gente, p. ex.), há um estigma linguístico-social gritante que marca negativamente as pessoas que não produzem concordância nominal (e também a verbal, cf. Naro \& Scherre, 1999) no Brasil. (MENON; FAGUNDES; LOREGIAN-PENKAL, 2010, p. 158)

De maneira geral, os estudos sociolinguísticos têm presumido o efeito da escola a partir do resultado da distribuição das variantes em função do nível de escolarização dos falantes estratificados em uma amostra. No entanto, a perspectiva da produção é, muitas vezes, diferente da perspectiva da percepção. Como se fala vs. como se acha que fala vs. como se acha que se deve falar são três dimensões que devem ser consideradas quando se pensa em programas de ensino de língua materna. Isso implica numa diferença de efeitos da escolarização conforme as distinções entre os fenômenos: formas de prestígio vs. formas relativamente neutras; fenômenos socialmente estigmatizados vs. fenômenos 
imunes à estigmatização; fenômenos objeto do ensino escolar vs. fenômenos que escapam à atenção normativa; e fenômenos discursivos (ou no mais alto nível gramatical) vs. fenômenos da gramática (níveis gramaticais intermediários entre o fonológico e o discursivo) (VOTRE, 2004, p. 52-53).

As distinções propostas por Votre (2004) podem ser vistas por outro prisma: distinção dos fenômenos quanto à sensibilidade da avaliação social (em termos de prestígio, estigma e aparente neutralidade) e fenômenos que são canonicamente objeto de ensino escolar, por sua proximidade com a escrita (no nível fonomorfossintático).

A concordância é exemplar do segundo caso: o currículo escolar sistematicamente aborda o padrão de concordância, com os exercícios de "passe para o plural” (e "passe para o “feminino"”, mas este é outro caso, que merece uma discussão à parte, que não será feita aqui), enfatizando os plurais irregulares, ou, em termos dos estudos sociolinguísticos, contextos de maior saliência fônica. É o que apontam os resultados de Scherre e Naro (2006), na figura 2: "O aumento da concordância em função de exposição à fala de prestígio implica diminuição do efeito da saliência fônica" (SCHERRE; NARO, 2006, p. 110). Mas não deve ser apenas pela exposição à fala de prestígio; o fato de ser um conteúdo abordado sistematicamente na educação básica, com exercícios estruturais, deve ter sua parcela de contribuição. Some-se isso ao fato de a concordância ser um fenômeno no nível da consciência social; representativo do tratamento societal dado a este fenômeno é o que ficou conhecido entre os linguistas como "A polêmica do livro didático", com interpretações amplamente difundidas pela mídia de que o governo estava incentivando a falar errado, com respostas e análise acadêmicas que podem ser conferidas em Lucchesi (2011), Scherre (2013), Bagno (2013), Cavalcanti (2013), entre outros. O alvo das críticas foram as frases - em uma seção intitulada "escrever é diferente de falar" - "Nós pega o peixe"; "Os menino pega o peixe" e "Os livro ilustrado mais interessante estão emprestado", contextos com ausência de marcas explícitas de concordância verbal e nominal. 
Figuras 2 - Efeito da saliência fônica em função dos anos de escolarização no uso da concordância verbal e nominal em duas amostras aleatórias da comunidade do Rio de Janeiro em épocas diferentes

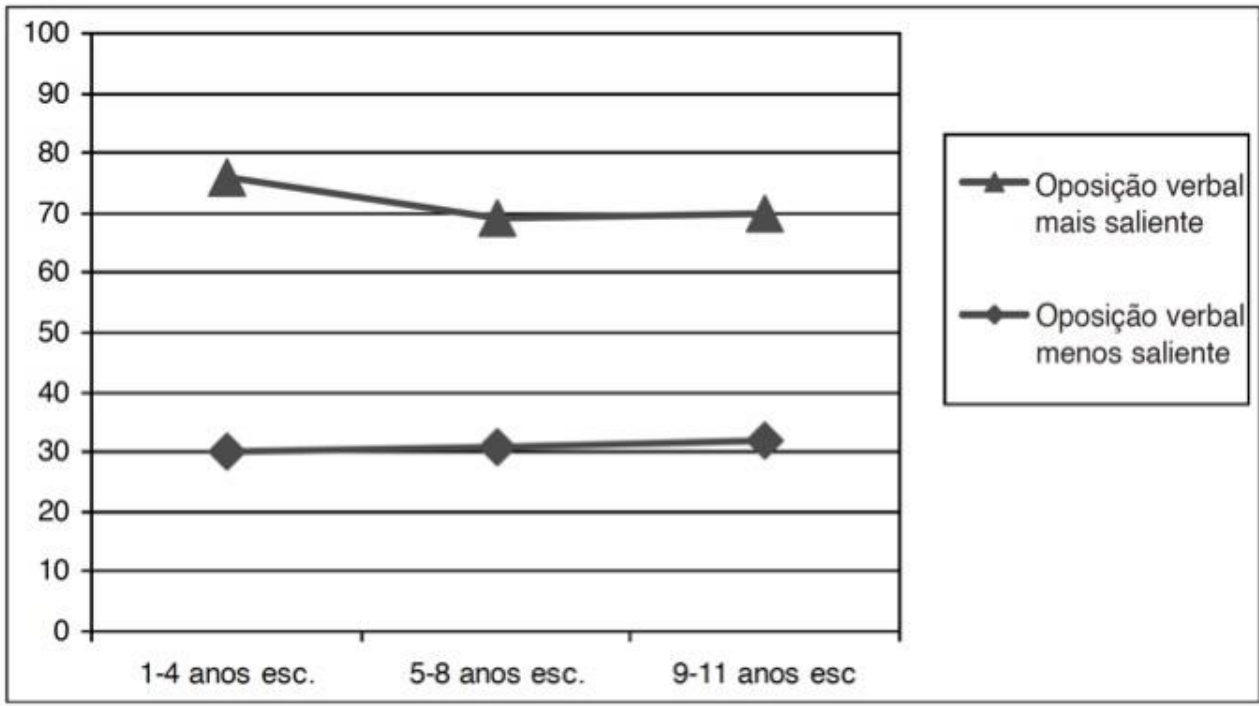

Efeito da saliência fônica no uso concordância verbal por anos de escolarização na amostra 1980-C.

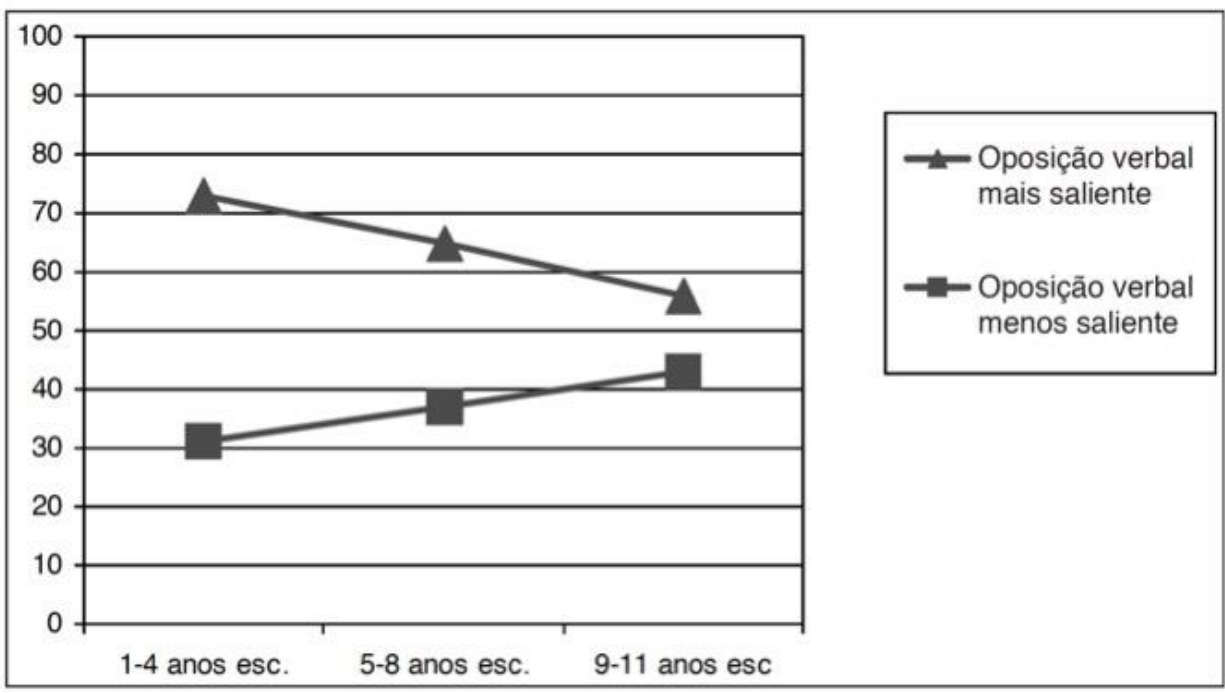
amostra 2000-C

Efeito da saliência fônica no uso concordância verbal por anos de escolarização na 


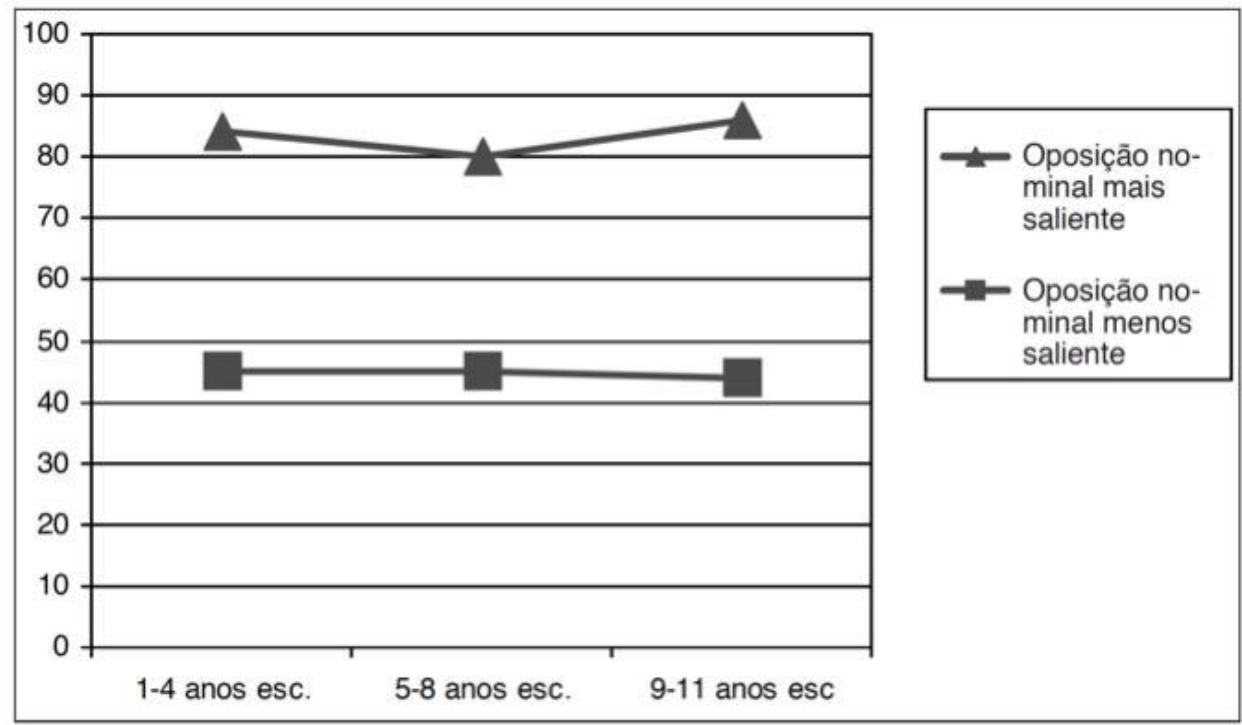

Efeito da saliência fônica no uso concordância nominal por anos de escolarização na amostra 1980-C.

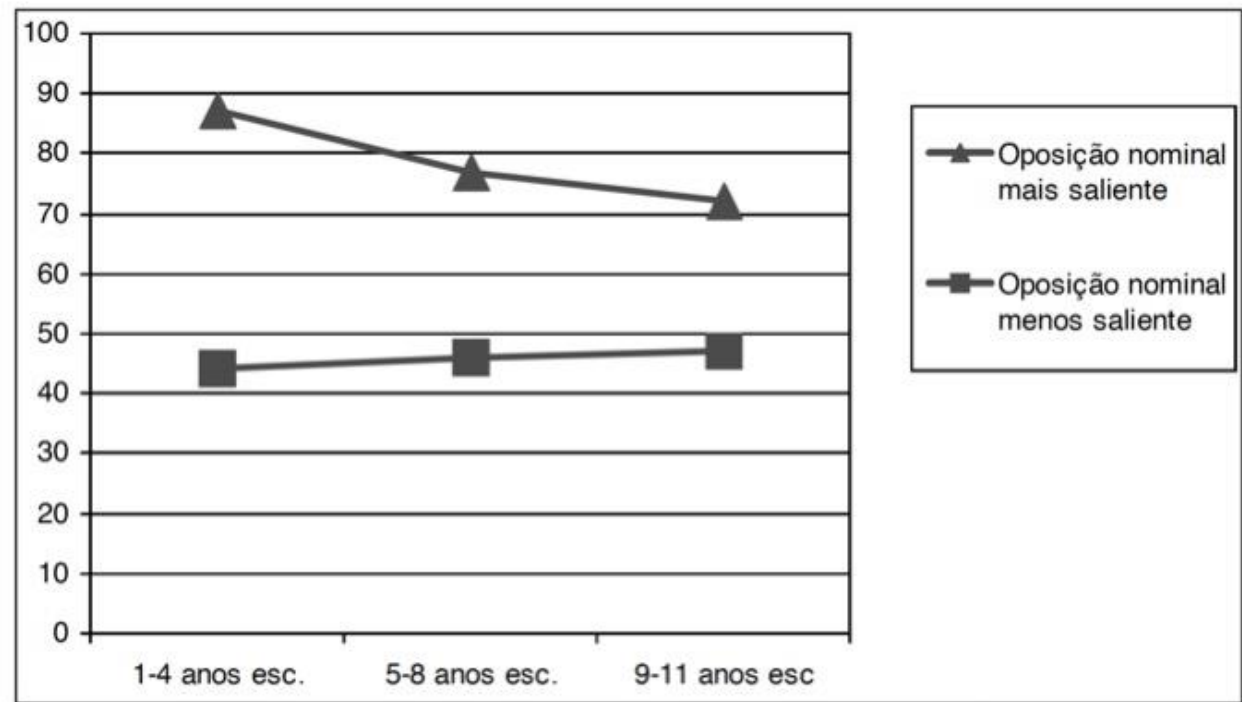

Efeito da saliência fônica no uso concordância nominal por anos de escolarização na amostra 2000-C.

Fonte: SCHERRE; NARO, 2006, p. 113-118 
Porém, como comparam Menon, Fagundes e Loregian-Penkal (2010), o status da variação na primeira pessoa do plural é diferente do da concordância de número. Os livros didáticos, mesmo os avaliados pelo Programa Nacional do Livro Didático, ainda apresentam um paradigma pronominal que não reconhece a forma "a gente" como pronome de $1^{a}$ pessoa do plural (BRANDÃO; VIEIRA, 2011). A ausência do "a gente" nos livros didáticos poderia, por hipótese, atuar como um refreador da mudança, no entanto, os dados de frequência apontam para outra direção: a forma é empregada, sistematicamente, por diferentes níveis de escolarização (cf. VIANNA; LOPES, 2015; FREITAG, 2016a).

Podemos, então, separar os fenômenos em duas categorias:

- Fenômenos que apresentam distribuição de frequência que sinaliza para efeito da escolarização, e que são objetos de atenção da escola e da sociedade, como é o caso da concordância de número.

- Fenômenos que apresentam distribuição de frequência que sinaliza para efeito da escolarização, e que não são objetos de atenção da escola e da sociedade, como é o caso da variação na primeira pessoa do plural.

No entanto, apenas a distribuição das frequências não é suficiente para elucidar o efeito da escola: ao mensurar a percepção sobre seu uso linguístico, falantes em fase final da educação básica e na educação superior fazem uso de uma variante, "a gente”, mas julgam melhor e até mesmo acreditam que usam a outra, "nós", que é a abonada pelos instrumentos normativos. Por isso, é preciso considerar não só a frequência de uso de uma variante, mas também como ela é julgada socialmente na comunidade.

Os estudos de crenças e atitudes - como se acha que se deve falar e como se acha que se fala (FREITAG et al., 2015, 2016; FREITAG, 2016a) - têm ganhado fôlego no Português Brasileiro nos últimos tempos, e podem atender às demandas de ensino de língua materna: não basta apenas ter os parâmetros de frequência de recorrência de uma dada variante, é preciso saber o valor social desta variante, em cada comunidade.

A tensão entre a dinâmica da estrutura da língua e a dinâmica social, especialmente o papel normatizador da escola, é evidenciada, não só por distribuição de 
frequências, mas pelo testemunho dos próprios falantes, que refletem a avaliação societal. Em fenômenos de mudança, a escola tende a conservar as variantes de prestígio, não por elas serem abonadas pelos instrumentos normativos, mas porque elas são objetos de avaliação social, consciente ou inconsciente. Por isso, como parâmetro de inclusão de um dado conteúdo no programa de ensino de língua materna, devem ser consideradas tanto a frequência de uso (que é o que os estudos sociolinguísticos de produção sistematizam), como a sua saliência quanto à avaliação social (obtida por meio de estudos de percepção sociolinguística). A correlação entre estes dois parâmetros gera uma matriz com quatro possibilidades de combinação (figura 3).

Figura 3 - Correlação entre frequência de uso e avaliação social

\begin{tabular}{|l|l|l|}
\hline \multicolumn{3}{|c|}{ Frequência de uso } \\
\hline $\begin{array}{l}\text { Avaliação social } \\
\text { (saliência) }\end{array}$ & {$[+$ frequente, + saliente $]$} & {$[$ frequente, - saliente $]$} \\
\cline { 2 - 3 } & {$[$-frequente, + saliente $]$} & frequente, - saliente $]$ \\
\hline
\end{tabular}

Um exemplo de fenômeno [+ frequente, + saliente] é a variação na concordância; a variação na primeira pessoa do plural é um fenômeno [+ frequente, - saliente]. ${ }^{4}$

A variação na segunda pessoa do singular, no Brasil, caminha na mesma direção da variação na segunda pessoa do plural: o pronome “vós” já não faz parte do repertório coloquial do brasileiro, mesmo em situações formais e escritas (MENON, 1995); e, em função de contatos dialetais, comunidades que ainda conservam o pronome "tu" veem a inserção gradual da forma "você". 5

\footnotetext{
${ }^{4} \mathrm{Na}$ oposição "nós" vs. "a gente", o estigma não é atribuído ao pronome propriamente dito, mas sim à relação de concordância estabelecida (cf. FREITAG, 2016a).

${ }^{5}$ A difusão da mudança na segunda pessoa é evidenciada pelo predomínio da forma "você". Scherre (2012, p. 16-17) sistematiza estudos sobre a variação na segunda pessoa do singular em 17 comunidades de fala do português brasileiro, evidenciando que há 5 de uso exclusivo de "você", 8 com alternância e predomínio de "você", três com alternância equilibrada entre as formas, e apenas uma com predomínio de "tu" (Florianópolis). Em sua sistematização diacrônica sobre a variação na segunda pessoa, Lopes (2008) identifica peças teatrais que não têm a forma "tu", mas todas as peças relacionadas apresentam a forma "você" na posição de sujeito.
} 
Assim como no caso do "a gente", a relação de prestígio/estigma quanto à segunda pessoa não é necessariamente com o pronome, mas com a relação de concordância estabelecida: "tu foste"| "tu fosse"| "tu foi". O estudo de Amaral (2003), na cidade de Pelotas, no Rio Grande do Sul, por exemplo, mostra que o uso do "tu" com concordância canônica tem uma aplicação muito baixa (tabela 1).

Tabela 1 - Aplicação da concordância na segunda pessoa em Pelotas, amostra VarX, estratificada quanto à classe social

\begin{tabular}{|c|c|c|c|}
\hline Classe média-alta & Classe média & Classe média-baixa & Classe baixa \\
\hline $12 \%$ & $8 \%$ & $7 \%$ & $6 \%$ \\
\hline
\end{tabular}

Fonte: AMARAL, 2003, p. 160

A distribuição das frequências quanto à estratificação por classe social sugere que o uso da forma "tu" com concordância canônica, tal como ensinada na escola, tem certo prestígio, dado que os percentuais, ainda que baixos, estão distribuídos proporcionalmente quanto à progressão de classe social (que considera o local de residência do informante, a sua profissão, escolarização). Em Florianópolis, outra comunidade também associada ao uso do "tu", a realização de "tu" com concordância canônica apresenta uma interessante inversão de escolarização (tabela 2): o uso de "tu” com concordância canônica é muito mais recorrente na fala de estudantes do ensino médio do que na fala de universitários.

Tabela 2 - Aplicação da concordância na segunda pessoa em Florianópolis, amostra Varsul (Monguillot e Floripa), estratificada quanto à escolarização

\begin{tabular}{|c|c|}
\hline Ensino superior & Ensino Médio \\
\hline $6 \%$ & $24 \%$ \\
\hline
\end{tabular}

Fonte: DAVET; CAMPOS-ANTONIASSI, 2014, p. 106 
E, em um estudo de reação subjetiva na mesma comunidade, o resultado do julgamento de universitários sugere que a realização de segunda pessoa sem concordância canônica, antes tida como estigmatizada, é avaliada como neutra, assim como a concordância canônica, antes tida como de prestígio (SOUZA; CHAVES, 2015).

O que leva estudantes do ensino médio a contrariarem a tendência de uso de universitários? A explicação do contato com a cultura letrada não é suficiente, pois, por hipótese, universitários estariam ainda mais expostos a ela. Este aumento de frequência artificial, na medida que a regra não é incorporada ao repertório do falante no decurso de sua vida - pode ser resultado de aulas de gramática. Este resultado responde a uma das perguntas propostas: qual é o papel da escola na mudança linguística? A escola atua como uma refreadora temporária da deriva. A pergunta que se segue é: a escola deve assumir explicitamente essa posição de guardiã da "pureza” da língua?

\section{A gramática e a escola}

Para discutir a relação entre a gramática e a escola, é pertinente retomar a discussão iniciada por Martins (2017). O texto tem como proposta discutir o que é “ensinar gramática”, especialmente no que tange ao que ensinar ou não ensinar. Para tanto, é trazido à discussão o posicionamento de Bagno (2013), especialmente no que diz respeito ao que "não ensinar na escola". Segundo Martins (2017, p. 106, grifos do original), Bagno faz "afirmações categóricas de que o ensino de determinadas formas, construções e variantes (algumas obsoletas mesmo na variante falada culta do português brasileiro) deve ser abandonado pela escola". Dentre essas, Martins destaca o uso do "vós", argumentando que "tal sistema precisa ser recuperado e ensinado na escola", pois “É a escola o lugar em que tais formas podem/devem ser recuperadas!" e que “abandonar a formalização de um ensino que recupere as formas de vós é negar ao aluno o acesso a bens culturais para os quais tal conhecimento certamente será requerido" (MARTINS, 2017, p. 107).

Recuperar formas da língua é torná-las objeto de ensino formal e ativo, com atividades interventivas que alterem o padrão de recorrência de uma variante em 
processo de obsolescência. O argumento para a recuperação das formas é permitir o acesso a bens culturais. Vieira e Feire (2014, p. 112) defendem que, "nas atividades escolares de leitura - de textos não literários a literários -, o espectro de variação pode ser bem maior [...], motivo pelo qual a escola não pode ignorar nenhuma das formas de cada fenômeno variável, ainda que elas não sejam produtivas nem na língua falada, nem na escrita jornalística". Não ignorar é diferente de recuperar as formas, em termos de projeto pedagógico: não ignorar pode significar a exposição ao conhecimento passivo sobre a existência das formas, em uma dada diacronia ou em uma região dialetal; recuperar as formas da língua significa transformá-las em objeto de intervenção ativa: “Ora, mesmo sabendo que a conjugação em vós não pertença à fala ou à escrita português culto brasileiro, porque perdemos um sistema de formas mais especificadas para a segunda pessoa do plural, tal sistema precisa ser recuperado e ensinado na escola" (MARTINS, 2017, p. 106). A questão subjacente a uma agenda de ensino de gramática é o limite da pluralidade de normas: se não pertence nem à fala nem à escrita, como muitas outras construções, até onde irá a recuperação de formas da língua pela escola? Temos que ter memória diacrônica até o português medieval?

No caso de "tu", em comunidades que ainda o conservem no sistema da segunda pessoa, a escola deve insistir na concordância canônica, que tem padrões de recorrência baixo, mesmo entre falantes mais escolarizados? O tratamento de um fenômeno de baixa recorrência, como "tu" com concordância canônica, não deve ser o mesmo dado a um fenômeno de alta recorrência, seja socialmente saliente, como a concordância de número, ou neutro, como a variação na primeira pessoa.

O "convívio democrático e tranquilo" da pluralidade de normas (BAGNO, 2013, p. 202) requer o equacionamento entre frequência de uso e avaliação social, sob pena de a escola gerar padrões artificiais de uso, como apresentado no estudo de Davet e CamposAntoniassi (2014), e que, ao invés do empoderamento para a formação cidadã, pode gerar agressão à escolha linguística da comunidade.

Martins (2017) apresenta um resultado na direção de sua proposta de recuperação de forma e seu ensino na escola com um trabalho desenvolvido no âmbito do Profletras, 
realizado por Xavier (2015). ${ }^{6}$ O fenômeno em questão é o objeto anafórico de $3^{a}$ pessoa no português. O ponto de partida foi a constatação de que "a forma mais utilizada mesmo na fala culta do brasileiro letrado é o objeto nulo e tal forma não é contemplada pelo ensino formal na escola" (MARTINS, 2017, p. 109). Foi desenvolvida uma sequência didática para alunos do $9^{\circ}$ ano do ensino fundamental de uma escola pública de Natal/RN, e foram coletados dados escritos da realização do objeto anafórico de $3^{a}$ pessoa em três momentos: relato de um filme, relato de experiência pessoal e texto ficcional. Os dados da realização do fenômeno são apresentados na tabela 3, a partir dos dados dos gráficos 1-3 de Martins (2017).

Tabela 3 - Realização do objeto anafórico da $3^{\text {a }}$ pessoa em três situações

\begin{tabular}{|l|c|c|c|c|c|c|}
\hline & \multicolumn{2}{|l|}{ Relato de filme } & \multicolumn{2}{l|}{ Relato de experiência } & \multicolumn{2}{l|}{ Texto ficcional } \\
\hline Pronomes clíticos & 4 & $5 \%$ & 1 & $3 \%$ & 45 & $45 \%$ \\
\hline Pronomes nominativos & 6 & $7 \%$ & 5 & $16 \%$ & 3 & $3 \%$ \\
\hline Sintagmas nominais & 45 & $51 \%$ & 8 & $25 \%$ & 42 & $42 \%$ \\
\hline Objetos nulos & 33 & $37 \%$ & 18 & $56 \%$ & 10 & $10 \%$ \\
\hline Total & $88^{7}$ & $100 \%$ & 32 & $100 \%$ & 100 & $100 \%$ \\
\hline
\end{tabular}

Fonte: Dados de Martins (2017) adaptados

Após os relatos, foram desenvolvidas atividades rotuladas como sendo de "ensino de gramática", mais especificamente, "a familiarização com os acusativos anafóricos"

\footnotetext{
${ }^{6}$ O Profletras é um programa de mestrado profissional em rede na área de ensino de Língua Portuguesa, induzido pela Capes e dirigido a professores do ensino fundamental da rede pública. Consta em seu currículo original a disciplina Gramática, Variação e Ensino (45h/a), de caráter obrigatório.

7 No original, são relatadas 85 ocorrências, mas a soma da descrição das variantes totaliza 88 .
} 
(MARTINS, 2017, p. 109). ${ }^{8}$ O resultado foi o preenchimento de objetos nulos em padrões artificiais, ou seja, padrões de recorrência que não encontram correlato em variedades escritas do português, como podemos ver na tabela 4. Freire (2005), ao investigar a realização do objeto anafórico na escrita dita padrão do Português Brasileiro e do Português Europeu, evidencia diferenças na distribuição de variantes e conclui que "não se pode negar a ampla infiltração das variantes alternativas aos clíticos nos textos produzidos pelas novas gerações de escritores" (FREIRE, 2005, p. 191).

Tabela 4 - Comparação dos resultados de realização do objeto anafórico na escrita nas variedades brasileira (PB) e europeia (PE) do português e os resultados de escrita ficcional de Xavier (2005)

\begin{tabular}{|l|c|c|c|c|c|c|}
\hline & \multicolumn{2}{|l|}{ PE (FREIRE, 2005) } & \multicolumn{2}{l|}{ PB (FREIRE, 2005) } & \multicolumn{2}{l|}{ (XAVIER, 2015) } \\
\hline Pronomes clíticos & 282 & $77 \%$ & 189 & $47 \%$ & 45 & $45 \%$ \\
\hline Pronomes nominativos & - & - & 32 & $8 \%$ & 3 & $3 \%$ \\
\hline Sintagmas nominais & 40 & $11 \%$ & 58 & $14 \%$ & 42 & $42 \%$ \\
\hline Objetos nulos & 44 & $12 \%$ & 127 & $31 \%$ & 10 & $10 \%$ \\
\hline Total & 366 & $100 \%$ & 406 & $100 \%$ & 100 & $100 \%$ \\
\hline
\end{tabular}

Dados de Freire (2005, p. 106) e Martins (2017, p. 94), adaptados

O resultado do desenvolvimento da sequência didática de Xavier (2015) levou os alunos a continuar produzindo as variantes alternativas, já presentes em sua gramática, e que foram utilizadas nas primeiras produções, conforme a tabela 3. No entanto, os

\footnotetext{
8 "(i) de desenvolver na escrita desses alunos o conhecimento linguístico como atividade epilinguística no que diz respeito a aspectos gramaticais do acusativo e do acusativo anafórico em português; (ii) de trabalhar com diferentes normas do português, percorrendo diferentes gêneros textuais que contemplassem as diferentes variantes em questão e (iii) de compreender a função textual das variantes em questão na construção da significação geral do texto" (MARTINS, 2017, p. 110-111). No entanto, os resultados apresentados focam apenas a questão do incremento de frequência de uso de algumas variantes vs. o recuo na frequência de uso de outras variantes. Após uma atividade de instrução sobre o uso de clíticos e o preenchimento do objeto, o aumento da frequência destas formas é uma consequência óbvia no espaço escolar: o professor ensina, os alunos replicam. A questão que não foi explorada é o que esse novo conhecimento trouxe para a significação geral do texto, o que não é mensurado pela frequência de uso.
} 
padrões distribucionais são artificiais, na medida em que os estudantes de Natal/RN, enquanto se aproximam do padrão de frequência de uso de pronomes clíticos do PB (47\% e 45\%), se aproximam também do padrão de frequência de uso de objeto nulo do PE (12\% e 10\%), e "criam" um novo padrão de frequência de uso de sintagma nominal (42\%), destoante dos padrões do PE (11\%) e do PB (14\%), para contextos de escrita formal, como as amostras de ambos os estudos.

Em um estudo descritivo sobre a gramática do letrado, Kato (2005, p. 136) explica que a escola assume a função de "recuperar as perdas linguísticas", partindo da premissa de que "as inovações são apropriadas para a fala, mas não para a escrita". Reportando um estudo sobre o papel da escola nos clíticos, o cruzamento de resultados diacrônicos e aprendizagem escolar sugere que a "escola recupera quantitativamente os clíticos do século XVII, mas a posição do clítico é a inovadora” (KATO, 2005, p. 136). Assim, “embora a escola procure recuperar a gramática do passado, consegue simulá-la apenas parcialmente, produzindo um conhecimento diferente daquele que o falante do século XVIII obteve no desenvolvimento da fala" (KATO, 2005, p. 147). Kato vai além e afirma que "a gramática do letrado brasileiro, no que diz respeito a clíticos, não corresponde nem a uma gramática de um falante letrado do passado e nem à de um letrado português" (KATO, 2005, p. 138). O resultado obtido por Xavier (2015) ratifica a conclusão de Kato (2005) em relação ao papel da escola, ao gerar um padrão de frequências de uso artificial para a comunidade. Mudar o padrão de uso de uma dada construção artificialmente não seria também uma forma de substituir a variedade do aluno? Ampliar o repertório significa não só introduzir novas formas, mas também apresentar os seus padrões distribucionais em função dos contextos, o que se torna ainda mais latente em fenômenos cujas formas inovadoras e canônicas, como evidenciado nos dados de diagnóstico de Xavier (2015), já estão presentes no repertório dos alunos. Outra questão a ser averiguada é a efetividade da intervenção didática quanto à persistência desse uso: após quatro semanas, os alunos ainda utilizariam estes padrões nessa frequência?

Para o ensino produtivo de clíticos, Freire (2005) sugere encaminhamentos ao professor: 
(a) ter consciência do atual processo de mudança por que passa o sistema linguístico brasileiro, o que consequentemente aumenta no Brasil a natural distância que sempre existiu entre fala e escrita; (b) levar os seus alunos ao contato direto com textos produzidos pela imprensa, que revelam a sensibilidade das novas gerações de letrados a respeito do que efetivamente vem a ser a norma culta brasileira usada em eventos de letramento. (FREIRE, 2005, p. 191)

Novamente, o “convívio democrático e tranquilo entre as formas” (BAGNO, 2013, p. 202) requer o equacionamento entre frequência de uso e avaliação social. O objeto nulo não parece ser socialmente estigmatizado. Por outro lado, os pronomes clíticos costumam ser objeto de avaliação social, com orientações explícitas quanto ao seu uso em comandos paragramaticais, inclusive em material institucional. ${ }^{9}$ No entanto, com a aplicação de um teste de correção de sala de aula, visando identificar se professores de Língua Portuguesa da rede pública de Natal/RN corrigem a colocação proclítica, Moura (2013) conclui que:

não encontramos um índice tão alto de correção da próclise nesse contexto [início de oração]. Esperávamos que a maioria dos professores a corrigisse; porém, percebemos um verdadeiro impasse na correção, com quantidades iguais de professores que a corrigiram e que não a corrigiram (50\%). Isso nos sugere que a próclise a V1 [em início de oração], nos textos escritos escolares, não é mais considerada um dos grandes erros gramaticais quando o professor corrige textos de alunos, e não é levado, explicitamente, a monitorar a colocação. [...]

Em relação ao contexto SV - próclise depois de sujeito -, o resultado das correções foi unânime: nenhum dos professores a corrigiu no texto indicado. Isso significa que a escola não é sensível à norma-padrão nesse contexto. (MOURA, 2013, p. 113)

\footnotetext{
${ }^{9}$ Apenas a título de exemplificação da força da avaliação social, observe-se que o Conselho Nacional de Justiça publicou uma coletânea intitulada "Dicas de português", com orientações sobre a "licitude" do uso dos pronomes átonos em posição proclítica: "A tendência para a próclise na língua falada atual é predominante, mas iniciar frases com pronomes átonos não é lícito numa conversação formal. Por exemplo: Linguagem Informal: Me alcança a caneta. Linguagem Formal: Alcança-me a caneta." (Disponível http://www.cnj.jus.br/files/conteudo/destaques/arquivo/2015/07/c9c2fa58f9872b372ac598d66a3d8237.pdf)
} 
Estes resultados evidenciam que a regra geral da colocação pronominal, “o clítico sempre vem anteposto ao verbo principal” (BAGNO, 2013, p. 231), está incorporada ao conjunto de regras que os professores de Língua Portuguesa da rede pública de Natal/RN, a despeito de prescrições gramaticais e a avaliação social subjacente.

As conclusões decorrentes dos resultados de Moura (2013) quanto ao nível de consciência da regra da próclise podem ser estendidas ao objeto anafórico: será que os professores têm consciência do objeto nulo e lhe atribuem valor estigmatizado para interpor um padrão de frequência de uso tão baixo? Ou é resultado de uma prescrição ao extremo: a escola assumindo o papel de guardiã da língua, resgatando formas em desuso e refreando a mudança? Se a sugestão de ensino dada por Moura (2013, p. 117) - de que "substituir a lista enfadonha de regras a serem memorizadas pela observação do uso dos clíticos em textos orais e escritos pode ser o início de um ensino gramatical mais eficiente [efetivo]", for adotada - , o padrão de recorrência da próclise, em termos de frequência de uso, será muito diferente do que se a estratégia didática adotada for o ensino das regras, inclusive nos contextos em que Martins (2017, p. 107) advoga que "a ênclise ainda é bastante recorrente [...], como em construções passivas ou com o pronome se indeterminador".

A necessidade de equacionamento entre frequência de uso e avaliação social fica evidente quando observamos um fenômeno linguístico de tão baixa frequência quanto o "vós", a mesóclise, padrão de colocação pronominal ausente na fala e muito raro na escrita no Português Brasileiro, que teve incremento em sua frequência de uso impulsionado por um único falante, Michel Temer. No entanto, a avaliação social deste uso, abonado pelas gramáticas e presente nos livros didáticos de língua portuguesa (mas proibido pelos manuais de redação e estilo de jornais), fez com que o próprio falante mudasse seu padrão de comportamento:

Após críticas e piadas, o presidente Michel Temer disse, em tom de brincadeira, que não usará mais a mesóclise. 
Em seu discurso de posse, Temer usou a expressão "...sê-lo-ia pela minha formação...", e o uso incomum do pronome levou a uma enxurrada de memes e deboches.

Nesta sexta (30), Temer comentou, divertindo-se, que não usaria mais a mesóclise.

"Ontem li um artigo de um cidadão me criticando pelo fato de eu falar bem o português. Não uso mais mesóclise", disse.

"Eu tomo a liberdade de fazê-lo, ou melhor dizer [risos]... Porque essas coisas, elas ganham vulto, certas ideias equivocadas são divulgadas e daqui a pouco sou eu o inadequado."

(Disponível em: <http://www1.folha.uol.com.br/poder/2016/09/1818344apos-criticas-e-memes-temer-diz-que-evitara-o-uso-de-mesoclise.shtml>)

Promover o uso artificial das colocações pronominais, estimulando os clíticos, pode levar a um julgamento social (consciente) ou ao abandono do uso quando em contraste com a frequência real do fenômeno (inconsciente). Retomando as perguntas propostas para discussão neste artigo, qual é o papel da escola? É papel da escola promover o incremento de frequência artificialmente, destoando dos padrões da comunidade? Ou é papel da escola promover o conhecimento da regra variável nos termos de frequência da sua variabilidade: tal forma existe e é usada em certos contextos, com certas finalidades?

Expor o aluno ao contato com pluralidade de normas - conhecimento passivo não é o mesmo que recuperar formas da língua, como objeto ativo de aprendizagem. Se assim o for, o repertório de normas é infinito e, no caso dos objetos anafóricos, teríamos que trazer propostas que deem conta, por exemplo, de uma frase que é dita (e escrita) hoje como "Dá pra mim a caneta" vire "Dê-ma", com um mesmo clítico que retoma objeto direto e indireto, como costuma ainda acontecer no português europeu. Ao entrar em contato com um texto com formas de realização desta natureza, o aluno precisa de conhecimento passivo sobre a língua, e não ser alvo de uma intervenção pedagógica que o faça assumir este uso ativamente. Nesse sentido, "não tem cabimento ensinar a conjugação nas pessoas de tu [na regiões dialetais do Brasil em que este pronome ainda persiste] e de vós [em todo o Português Brasileiro]" (BAGNO, 2013, p. 205 excertos acrescidos), nem da mesóclise. $E$ também não tem cabimento elevar a frequência de uso artificialmente de uma forma variante, como acontece no caso ilustrado no estudo de Martins (2017) para a realização do objeto anafórico. Considerando as diretrizes para o 
ensino de língua portuguesa presentes nos Parâmetros Nacionais de Língua Portuguesa e reforçadas (até a presente versão) na Base Nacional Comum Curricular, não pode ser papel da escola recuperar e ensinar sistemas com o intuito de elevar a frequência artificialmente, gerando um uso totalmente anômalo e desvinculado da realidade da língua, ou elevá-la tal como em sincronias passadas. Informações sobre a frequência e os contextos de uso fazem parte da gramática do falante; as formas o falante já conhece; o que a escola precisa propiciar é o contato com situações reais de uso, para que o aluno organize os padrões de recorrência em função do contexto, tal como sugerem Freire (2005) para o objeto acusativo, e Moura (2013) para a colocação pronominal.

\section{Conclusão}

A reflexão sobre o papel da escola na mudança linguística e sobre o papel da gramática na escola permite corroborar a afirmação de Bagno (2013) de que a escola deve ensinar o que o aluno não sabe; e o que o aluno não sabe não são as formas, mas sim os padrões de distribuição dessas formas, a sua frequência de recorrência e os seus contextos de uso. Por isso, "o ensino de determinadas formas, construções e variantes (algumas obsoletas mesmo na variante falada culta do português brasileiro) deve ser abandonado pela escola" (MARTINS, 2017). Considerando as diretrizes norteadoras do ensino de língua portuguesa, não é papel da escola recuperar formas da língua, mas sim dar a conhecer a pluralidade de normas. Há uma diferença entre conhecimento ativo e conhecimento passivo sobre a língua: para o "acesso a bens culturais", o conhecimento passivo a respeito do uso é suficiente. Se a pluralidade de normas é compreendida como recuperar formas da língua, a escola precisa repensar até onde vai na diacronia, e aí "dêma" entra no conjunto de conteúdos a serem ensinados na escola.

Os estudos sociolinguísticos de produção têm trazido contribuição significativa para o entendimento do que é o Português Brasileiro, em oposição ao Português Europeu, ao tempo que têm subsidiado a proposição de novas regras nas gramáticas. Moura (2013) destaca que as gramáticas de Castilho (2010) e de Perini (2010) trazem a 
inclusão da regra da próclise em início de frase; do mesmo modo o faz Bagno (2013)..$^{10} \mathrm{O}$ controle da escolarização tem permitido predizer aspectos da avaliação social do fenômeno, nas seguintes direções: fenômenos sociolinguísticos sensíveis à escolarização >> nível de consciência; fenômenos sociolinguísticos não sensíveis à escolarização >> nível da neutralidade. Ainda assim, este controle parte, em muitos casos, de uma idealização homogeneizante de escola, sem considerar que a escola reflete e replica as estruturas sociais.

No entanto, apenas a distribuição das frequências não é suficiente; os estudos sociolinguísticos de percepção devem também compor a agenda de discussão dos programas de ensino de língua materna. A correlação entre a frequência de uso (que é o que os estudos sociolinguísticos de produção sistematizam) e a sua saliência quanto à avaliação social (obtida por meio de estudos de percepção sociolinguística) permite romper com o anacronismo que a escola vem perpetuando, ao gerar padrões artificiais de uso e assumindo o papel de guardiã da “pureza” da língua.

\section{Referências}

AMARAL, Luís Isaías. Centeno do. A concordância verbal de segunda pessoa do singular em Pelotas e suas implicações lingüísticas e sociais. 2003. Tese (Doutorado em Letras) Universidade Federal do Rio Grande do Sul, Instituto de Letras, Porto Alegre, 2003.

BAGNO, Marcos. Gramática de bolso do português brasileiro. São Paulo: Parábola, 2013.

BRANDÃO, Silvia Figueiredo; VIEIRA, Silvia Rodrigues. Ensino de gramática: descrição e uso. São Paulo: Contexto, 2011.

CALLOU, Dinah; LOPES, Célia. Contribuições da sociolinguística para o ensino e a

\footnotetext{
${ }^{10}$ No entanto, embora as gramáticas contemporâneas do português brasileiro tenham avançado, ao contemplar uma norma brasileira, é preciso reconhecer que as contribuições advindas de descrições linguísticas que estão presentes nestas gramáticas não são oriundas de empreendimentos genuinamente sociolinguísticos: os dados que ilustram a gramática de Bagno (2013) e Castilho (2010) são do projeto NURC (Norma Urbana Culta), com registros de falantes considerados "cultos" nas grandes capitais brasileira no final da década de 1960 e início de 1970. A sociolinguística brasileira falhou ao não ter um projeto de corpus mínimo, como o Alib (Atlas Linguístico do Brasil) têm, que subsidie uma descrição das normas linguísticas brasileiras em contextos de igualdade metodológica, a fim de possibilitar análises contrastivas e subsidiar, de modo mais efetivo, programas de ensino de língua portuguesa.
} 
pesquisa: a questão da variação e mudança linguística. Revista do GELNE, v. 5, n. 1, p. 6374, 2004.

CASTILHO, Ataliba Teixeira de. A nova gramática do português brasileiro. São Paulo: Contexto, 2010.

CAVALCANTI, Jauranice Rodrigues. As faces de uma polêmica: o episódio do livro didático Por uma vida melhor. DELTA, v. 29, n. esp, p. 485-501, 2013.

COAN, Márluce; FREITAG, Raquel Meister Ko. Sociolinguística variacionista: pressupostos teórico-metodológicos e propostas de ensino. Domínios de Lingu@gem, v. 4, n. 2, p. 173194, 2010.

DAVET, Julie; CAMPOS-ANTONIASSI, Paula Isaias. Variação na concordância verbal de segunda pessoa do singular: um estudo da fala florianopolitana. Working Papers em Lingüística, v. 15, n. 1, p. 95-111, 2014.

DUARTE, Maria Eugenia; RAMOS, Jania Martins. O papel da sociolinguística no ensino da escrita padrão. Revista do GELNE, v. 5, n. 1/2, p. 91-96, 2003.

ECKERT, Penelope. Jocks and burnouts: social categories and identity in the high school. New York: Teachers College Press, 1989.

FREIRE, Gilson Costa. A realização do acusativo e do dativo anafóricos de terceira pessoa na escrita brasileira e lusitana. 2005. Tese (Doutorado em Língua Portuguesa)

Universidade Federal do Rio de Janeiro, Faculdade de Letras, Rio de Janeiro, 2005.

FREITAG, Raquel Meister Ko et al. Como o brasileiro acha que fala? desafios e propostas para a caracterização do" português brasileiro". Signo y seña, n. 28, p. 65-87, 2015.

FREITAG, Raquel Meister Ko et al. Como os brasileiros acham que falam? Percepções sociolinguísticas de universitários do Sul e do Nordeste. Todas as Letras, v. 18, n. 2, p.6684, 2016.

FREITAG, Raquel Meister Ko. Idade: uma variável sociolingüística complexa. Línguas \& Letras, v. 6, n. 11, p. 105-121, 2005.

FREITAG, Raquel Meister Ko. O "social” da sociolinguística: o controle de fatores sociais. Diadorim, v. 8, p. 43-58, 2011.

FREITAG, Raquel Meister Ko. Sociolinguística no/do Brasil. Cadernos de Estudos Linguísticos, v. 58, n. 3, p. 445-460, 2016 a. 
FREITAG, Raquel Meister Ko. Uso, crença e atitudes na variação na primeira pessoa do plural no Português Brasileiro. DELTA, v. 32, p. 889-917, 2016b.

GÖRSKI, Edair Maria; COELHO, Izete Lehmkuhl. Sociolingüística e ensino: contribuições para a formação do professor de língua. Florianópolis, Editora da UFSC, 2006.

GÖRSKI, Edair Maria; COELHO, Izete Lehmkuhl. Variação linguística e ensino de gramática. Working papers em Linguística, v. 10, n. 1, p. 73-91, 2009.

GÖRSKI, Edair Maria; FREITAG, Raquel Meister Ko Língua materna e ensino: alguns pressupostos para a prática pedagógica. In: SILVA, Camilo Rosa da (Org.). Ensino de português: demandas teóricas e práticas. João Pessoa: Ideia, 2007, p. 91-125.

GÖRSKI, Edair Maria; FREITAG, Raquel Meister Ko. O papel da sociolinguística na formação dos professores de Língua Portuguesa com língua materna. In: TAVARES, Maria Alice; MARTINS, Marco Antonio. (Org.). Contribuições da Sociolinguística e da linguística histórica para o ensino de língua portuguesa. Natal: EDUFRN, 2013. p. 11-52. Coleção Ciências da Linguagem Aplicadas ao Ensino, volume V.

GUY, Gregory R.; ZILLES, Ana Maria Stahl. O ensino da língua materna: uma perspectiva sociolinguística. Calidoscópio, v. 4, n. 1, p. 39-50, 2006.

KATO, Mary. A gramática do letrado: questões para a teoria gramatical. In: MARQUES, Mary et al. (Org.). Ciências da linguagem: trinta anos de investigação e ensino. Braga: CEHUM, 2005, p. 131-145.

LEMLE, Miriam; NARO, Anthony Julius. Competências básicas do português: relatório final de pesquisa apresentado às instituições patrocinadoras - Fundação Mobral e Fundação Ford. Rio de Janeiro, 1977.

LOPES, Celia Regina dos Santos. Retratos da variação entre "você" e "tu" no português do Brasil: sincronia e diacronia. In: RONCARATI, Claudia; ABRAÇADO, Jussara (Org.). Português Brasileiro II - contato lingUístico, heterogeneidade e história. Niterói: EDUFF, 2008, v. 2, p. 55-71.

LUCCHESI, Dante. Ciência ou dogma? o caso do livro do MEC e o ensino de língua portuguesa no Brasil. Revista Letras, v. 83, n. 1, p. 163-187, 2011.

MARTINS, Marco Antonio; VIEIRA, Silvia Rodrigues; TAVARES, Maria Alice. Ensino de português e sociolinguística. São Paulo: Contexto, 2014.

MARTINS, Marco Antonio. Em defesa do ensino de gramática na escola. Revista do GELNE, v. 19, n. 1, p. 103-117, 2017. 
MENON, Odete Pereira da Silva; FAGUNDES, Edson Domingos; LOREGIAN-PENKAL, Loremi. O que fazer com grupos de fatores não selecionados? O caso da concordância nominal no Paraná. Gragoatá, v. 15, n. 29, 2010.

MENON, Odete Pereira da Silva. O sistema pronominal do português do Brasil. Revista Letras, v. 44, p.91-106, 1995.

MOURA NEVES, Maria Helena de; CASSEB-GALVÃO, Vânia Cristina (Orgs.). Gramáticas contemporâneas do Português: com a palavra, os autores. São Paulo: Parábola, 2014.

MOURA, Elisabeth Silva de Vieira. SE inicia oração com pronomes clíticos? Atitudes linguísticas, na escola, em relação a padrões brasileiros de colocação pronominal. 2013. Dissertação (Mestrado em Estudos da Linguagem) - Universidade Federal do Rio Grande do Norte, 2013.

PERINI, Mário. Gramática do português brasileiro. São Paulo: Parábola, 2010.

SCHERRE, Maria Marta Pereira; NARO, Anthony Julius. Mudança sem mudança: a concordância de número no português brasileiro. Scripta, v. 9, n. 18, p. 107-129, 2006.

SCHERRE, Maria Marta Pereira. Padrões sociolinguísticos do português brasileiro: a importância da pesquisa variacionista. Tabuleiro de Letras, n. 4, p.1-32, 2012.

SCHERRE, Maria Marta Pereira. Verdadeiro respeito pela fala do outro: realidade possível. Revista Letra, v. 8, n. 1, p. 51-62, 2013.

SOUZA, Christiane Maria Nunes de; CHAVES, Raquel Gomes. A avaliação da concordância verbal com o pronome tu em Florianópolis. Working Papers em Linguística, v. 16, n. 1, p. 170-189, 2015.

VIANNA, Juliana de Segadas, LOPES, Célia Regina dos Santos. Variação dos pronomes "nós" e "a gente". In: ABRAÇADO, Jussara; MARTINS, Marco Antonio (Orgs.).

Mapeamento sociolinguístico do português brasileiro. São Paulo: Editora Contexto, 2015, p. 109-132.

VIEIRA, Silvia Rodrigues; FREIRE, Gilson Costa. Variação morfossintática e ensino de português. In: MARTINS, Marco Antonio; TAVARES, Maria Alice; VIEIRA, Silvia Rodrigues (Orgs.). Ensino de português e sociolinguística. São Paulo: Contexto, 2014, p. 81-104.

VIEIRA, Silvia Rodrigues. Três eixos para o ensino de gramática: uma proposta experimental. In: NORONHA, Claudianny Amorim; SÁ Jr., Lucrécio Araújo. (Org.). Escola, ensino e linguagens: propostas e reflexões. Natal: EDUFRN, 2017, v. 1, p. 78-104. 
VOTRE, Sebastião Josué. Relevância da variável escolaridade. In: MOLLICA, Maria Cecilia; BRAGA, Maria Luiza (Orgs.). Introdução à sociolinguística: o tratamento da variação. São Paulo: Contexto, 2004, p. 51-57, 2004.

XAVER, Alice Carla Marcelino Xavier. $O$ acusativo anafórico e normas do português na escola: uma proposta de intervenção para o ensino de gramática. 2015. Dissertação (Mestrado em ProfLetras) - Universidade Federal do Rio Grande do Norte, Natal, 2015.

ZILLES, Ana Maria Stahl; FARACO, Carlos Alberto. Pedagogia da variação linguística. São Paulo: Parábola, 2015. 